Wright State University

CORE Scholar

12-14-1993

\title{
Evidence for Day-to-Night Ion Transport at Low Solar Activity in the Venus Pre-Dawn lonosphere
}

\author{
J. F. Brannon \\ Jane L. Fox \\ Wright State University - Main Campus, jane.fox@wright.edu \\ H. S. Porter
}

Follow this and additional works at: https://corescholar.libraries.wright.edu/physics

Part of the Astrophysics and Astronomy Commons, and the Physics Commons

\section{Repository Citation}

Brannon, J. F., Fox, J. L., \& Porter, H. S. (1993). Evidence for Day-to-Night Ion Transport at Low Solar Activity in the Venus Pre-Dawn lonosphere. Geophysical Research Letters, 20 (23), 2739-2742. https://corescholar.libraries.wright.edu/physics/336

This Article is brought to you for free and open access by the Physics at CORE Scholar. It has been accepted for inclusion in Physics Faculty Publications by an authorized administrator of CORE Scholar. For more information, please contact library-corescholar@wright.edu. 


\title{
Evidence for Day-to-Night Ion Transport at Low Solar Activity in the Venus Pre-Dawn Ionosphere
}

\author{
J. F. Brannon and J. L. Fox
}

State University of New York at Stony Brook

\author{
H. S. Porter
}

Furman University

Abstract. Periapsis of the Pioneer Venus spacecraft dropped below $180 \mathrm{~km}$ on August 28, 1892 near midnight, and 42 orbits of low altitude data at moderately low solar activity in the pre-dawn sector were obtained before contact was lost to the spacecraft in October, 1992. Through a combination of analysis of data from the PV orbiter ion mass spectrometer (OIMS) and modeling, we consider here what can be learned about the relative importance of plasma transport from the dayside and electron precipitation in maintaining the nightside ionosphere during the re-entry period. In particular, we examine here the atomic ion density profiles. We compute the average peak density of $\mathrm{O}^{+}$as a function of solar senith angle and determine what fluxes of atomic ions or precipitating electrons would be necessary to produce those values. We then compare model calculations of the ion densities to those observed during the re-entry period. We find that the low solar activity nightside ionosphere shows evidence of significant day-to-night plasma transport.

\section{INTRODUCTION}

The sources of the nightside ionosphere of Venus have been disputed over the last 15 years, but are now generally believed to be transport of atomic ions from the dayside and precipitation of electrons that have been observed in the umbra [e.g., Knudsen et al., 1980; Spenner et al., 1981; Cravens et al., 1983; Gringauz et al., 1979]. The former appears to dominate at high solar activity, and the latter at low solar activity [e.g. Knudsen, 1988; Kliore et al., 1991]. Re-entry of the Pioneer Venus (PV) orbiter occurred last fall when solar activity was declining; the average value of $F_{10.7}$ was 118 in September, 1992. During the first two years of the PV mission (1978-1980), when periapsis was maintained within the thermosphere-ionosphere, solar activity was near maximum.

Fox [1992] has discussed the chemistry of the Venus nightside ionosphere for the case in which the ionisation is maintained by plasma transport from the dayside. Fluxes of the atomic ions $\mathrm{O}^{+}, \mathrm{C}^{+}$, and $\mathrm{N}^{+}$were imposed at the upper boundary of a neutral model that is based on data from the PV orbiter neutral mass spectrometer (ONMS) [Niemann et al., 1980; Hedin et al., 1983]. The relative fluxes of the ions were assumed to be those that were observed at high altitudes on the dayside, but the $\mathrm{He}^{+}$densities were taken from measured values [Taylor et al., 1980]. We showed, as have others, that the $\mathrm{O}^{+}$peak densities are approximately

Copyright 1993 by the American Geophysical Union. proportional to the $\mathrm{O}^{+}$flux. The $\mathrm{O}_{2}^{+}$peak density is, however, proportional to the square root of the $\mathrm{O}^{+}$flux. At high solar activity, models that included only precipitation of the electrons that were observed at high altitudes on the nightside by the PV orbiter retarding potential analyser (ORPA) [Knudsen and Miller, 1985] or the Venera 9 and 10 plasma analyzers [Gringauz et al., 1977] could not reproduce the large observed $\mathrm{O}^{+}$densities at high altitudes [Cravens et al., 1983; Spenner et al., 1981; Fose et al., 1992]. The ratio of the $\mathrm{O}^{+}$maximum to that of $\mathrm{O}_{2}^{+}$theoretically could yield information about the sources of ionisation [Fox, 1892], but during the furst two years the spacecraft did not often penetrate to below the $\mathrm{O}_{2}^{+}$peak, which was observed to be in the 140-145 km range by the PV orbiter radio occultation (ORO) measurements [Kliore et al., 1991].

There has also been some question about absolute normalisation of the low altitude molecular ion densities mesaured by the OIMS. Miller et al. [1984] have suggested that the OIMS molecular ion densities near the ion peak at high solar activity are about twice the values measured by the ORPA. There is no evidence for such a problem with the atomic ion densities, which peak at higher altitudes. We have chosen here to examine the atomic ion density profiles measured by the OIMS to determine what can be inferred from them about the relative importance of electron precipitation and transport of plasma from the dayside in maintaining the nightside ionosphere at low solar activity.

We determine here the average $\mathrm{O}^{+}$maximum density as a function of solar zenith angle over the dawn sector from PV OIMS re-entry data. Using the VTS3 model of the nightside thermosphere for $F_{10.7}=118$ (moderately low solar activity) from Hedin et al. [1983], we then determine the relationship between $\mathrm{O}^{+}$flux and $\mathrm{O}^{+}$peak density. Since re-entry occurred in the pre-dawn region of the ionosphere, where the densities of light neutrals and ions are observed to maximise, we have expanded the model of Fox [1992] to include downward transport of $\mathrm{He}^{+}$as well. We derive an average downward flux over the solar senith angle range that was sampled in the re-entry portion of the mission. Since the ionosphere may be maintained mostly or partly by electron precipitation, this flux should be considered an upper limit. Assuming that the precipitating electrons have an energy spectrum similar to that measured by Knudsen and Miller [1985], we determine the electron fluxes that would be necessary to produce the observed average $\mathrm{O}^{+}$maximum. These numbers are also upper limits. We compare the model ionospheres for both plasma transport and electron precipitation.

\section{Data and Calculations}

We have computed the average ratios of $\mathrm{C}^{+}, \mathrm{N}^{+}$, and $\mathrm{He}^{+}$measured at high altitudes (180 to $250 \mathrm{~km}$ ) by the 
Table 1. Downward $\mathrm{O}^{+}$Flux on the Nightside of Venus Derived from Pioneer Venus OIMS Re-entry Data

\begin{tabular}{ccccccc}
\hline $\begin{array}{c}\text { SZA Range } \\
\text { (Degrees) }\end{array}$ & $\begin{array}{c}\text { Average Measured } \\
\mathrm{O}^{+} \text {Maximum } \\
\text { Density }\left(\mathrm{cm}^{-3}\right)\end{array}$ & $\begin{array}{c}\text { Average } \\
\mathrm{C}^{+} / \mathrm{O}^{+3}\end{array}$ & $\begin{array}{c}\text { Average } \\
\mathrm{N}^{+} / \mathrm{O}^{+3}\end{array}$ & $\begin{array}{c}\text { Average } \\
\mathrm{He}^{+} / \mathrm{O}^{+3}\end{array}$ & $\begin{array}{c}\text { Computed } \mathrm{O}^{+} \\
\text {Marimum } \\
\text { Density }\left(\mathrm{cm}^{-3}\right)^{4}\end{array}$ & $\begin{array}{c}\text { Inferred } \mathrm{O}^{+} \\
\text {Transport } \\
\text { Flux }\left(\mathrm{cm}^{-2} \mathrm{~s}^{-1}\right)\end{array}$ \\
\hline $110-120$ & $\mathbf{1 . 0 ( 3 )}$ & 0.12 & 0.17 & 0.59 & $1.5(3)$ & $6.7(6)$ \\
$120-130$ & $1.8(3)$ & 0.16 & 0.16 & 0.35 & $1.7(3)$ & $1.1(7)$ \\
$130-140$ & $2.3(3)$ & 0.23 & 0.18 & 0.63 & $1.9(3)$ & $1.2(7)$ \\
$140-150$ & $\mathbf{1 . 4}(2)$ & 0.23 & 0.20 & 0.31 & $1.7(3)$ & $4.9(6)$ \\
$150-160$ & $9.8(2)$ & 0.31 & 0.44 & 0.52 & $1.7(3)$ & $5.8(6)$ \\
$160-170$ & $9.2(2)$ & 0.12 & 0.47 & 0.28 & $1.4(3)$ & $6.6(6)$ \\
$170-180^{2}$ & $1.8(2)$ & 0.07 & 0.15 & 0.18 & $1.1(3)$ & $1.6(6)$ \\
\hline
\end{tabular}

${ }^{1}$ Read as $1.0 \times 10^{3}$

${ }^{2}$ One data point

${ }^{3}$ Columns labeled $\mathrm{C}^{+} / \mathrm{O}^{+}, \mathrm{N}^{+} / \mathrm{O}^{+}$and $\mathrm{He}^{+} / \mathrm{O}^{+}$are averages of the high altitude data $(180-250 \mathrm{~km})$.

${ }^{4}$ Calculated for an $\mathrm{O}^{+}$tranoport flux of $1.0 \times 10^{7} \mathrm{~cm}^{-2} \mathrm{~s}^{-1}$.

OIMS for orbits 5014 to 5055 to determine the ratio of the atomic ion fluxes to impose at the upper boundaries of the models. The measured values were averaged in ten degree solar senith angle bins, and are presented in Table 1. The average ratios over the whole range of the solar senith angles (weighted by area) for $\mathrm{He}^{+} / \mathrm{O}^{+}, \mathrm{C}^{+} / \mathrm{O}^{+}$, and $\mathrm{N}^{+} / \mathrm{O}^{+}$are $0.46,0.19$, and 0.23 , respectively. Models were constructed for each of the solar senith angle bins; the latitude chosen was $-10^{\circ}$, that appropriate to the re-entry period. Since the relationship between the $\mathrm{O}^{+}$flux and $\mathrm{O}^{+}$maximum for a given model is approximately linear, (and the curve must pass through the origin), it is sufficient to compute the $\mathrm{O}^{+}$ maximum for one flux in order to to determine the slope of the line. For each solar senith angle, we have computed the maximum in the $\mathrm{O}^{+}$density profile for a downward $\mathrm{O}^{+}$ flux of $1 \times 10^{7} \mathrm{~cm}^{-2} \mathrm{~s}^{-1}$. Those values and the $O^{+}$fluxes obtained by applying the linear relationship to the measured maxima are also shown in Table 1. When the solar zenith angles are weighted by area, the average $\mathrm{O}^{+}$flux obtained

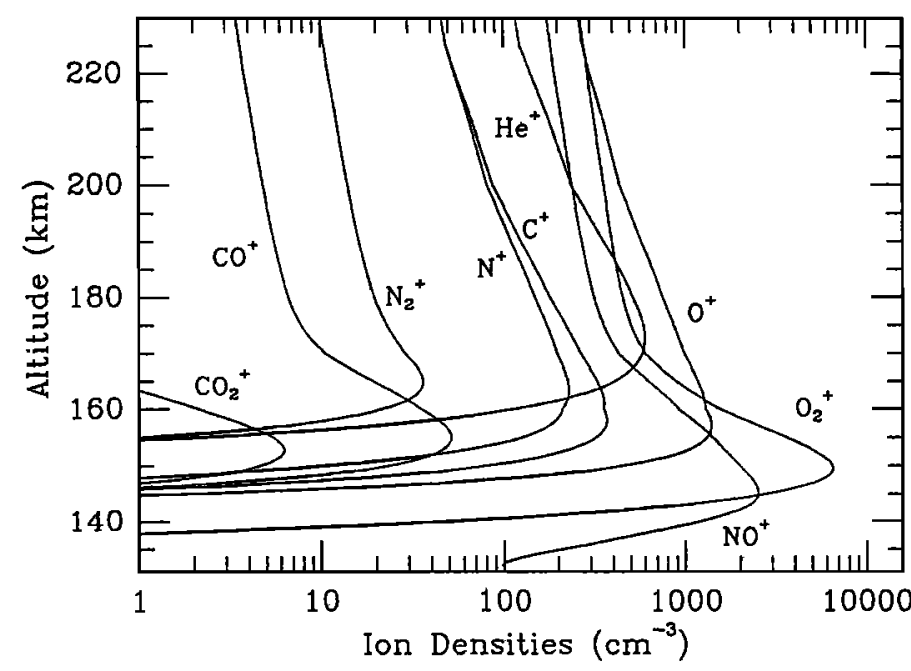

Fig. 1. Model of the Venus nightside ionosphere produced by nightward transport of ions for $145^{\circ}$ solar senith angle in the pre-dawn sector. The downward $\mathrm{O}^{+}$flux imposed at the upper boundary of the model is the average computed from the measured values of the $\mathrm{O}^{+}$maxima for the reentry data. The ratios of the fluxes of $\mathrm{C}^{+}, \mathrm{N}^{+}$, and $\mathrm{He}^{+}$ were determined from the measured density ratios at high altitudes. for the region of the dawn sector that is covered by the measurements is $8.1 \times 10^{6} \mathrm{~cm}^{-2} \mathrm{~s}^{-1}$. The calculation of this average is based on the assumption that the day-tonight ion fluxes depend only on solar senith angle and not on latitude. Since the in situ data are all in the equatorial region, this may not be a completely valid assumption.

The average $\mathrm{O}^{+}$flux for the first $600 \mathrm{PV}$ orbits (high solar activity) over a comparable area of the dawn sector is about $8.1 \times 10^{7} \mathrm{~cm}^{-2} \mathrm{~s}^{-1}$ [Brannon and Fox, to be submitted]. This value is smaller than the average over the whole nightside at high solar activity, which is about $1.3 \times 10^{8} \mathrm{~cm}^{-2} \mathrm{~s}^{-1}$, because the largest fluxes appear to be near the terminators, where there are no data for the re-entry period. Contact was lost with the spacecraft when periapsis was near 0430 local time. It appears, however, that the transport from the dayside is reduced by a factor of at least 10 from high to low solar activity.

The average solar senith angle for the re-entry data is about $145^{\circ}$. A model ionosphere was constructed for this solar senith angle with a downward flux of $\mathrm{O}^{+}$of $8.1 \times 10^{\circ}$ $\mathrm{cm}^{-2} \mathrm{~s}^{-1}$, the average derived for the re-entry region. A more complete description of the plasma transport model can be found in Fox [1992]. The computed ion density profiles are shown in Figure 1. The $\mathrm{O}^{+}$density peak in this model is $1.4 \times 10^{3} \mathrm{~cm}^{-3}$ at about $157 \mathrm{~km}$, and the $\mathrm{O}_{2}^{+}$peak is about $6.5 \times 10^{3} \mathrm{~cm}^{-3}$ near $149 \mathrm{~km}$. Because of the probable presence of electron precipitation, the ion fluxes inferred here should be considered upper limits.

It is also possible that the ionization is maintained by electron precipitation. Assuming that the energy distribution of the precipitating electrons is the same as the spectrum measured by Knudsen and Miller [1985] at high altitudes in the wake at high solar activity, we have computed also an auroral model ionosphere. We have imposed downward fluxes of electrons at the top of the same neutral model that we used for the plasma transport case. The energy degradation of the precipitating electrons is computed using a multi-stream electron transport code developed by Porter et al. [1987]. Electron-impact ionization of $\mathrm{CO}_{2}, \mathrm{~N}_{2}, \mathrm{CO}, \mathrm{O}, \mathrm{He}, \mathrm{C}$, and $\mathbf{N}$ are included. The cross sections used are referenced in Fox and Dalgarno [1979], Fox [1982; 1992], and Porter et al. [1987]. The production rates are shown in Figure 2.

We have determined the electron fluxes necessary to produce the observed average $\mathrm{O}^{+}$maximum for this model, and found that about $51 \%$ of the downward traveling portion of the spectrum measured by Knudsen and Miller [1985] pro- 


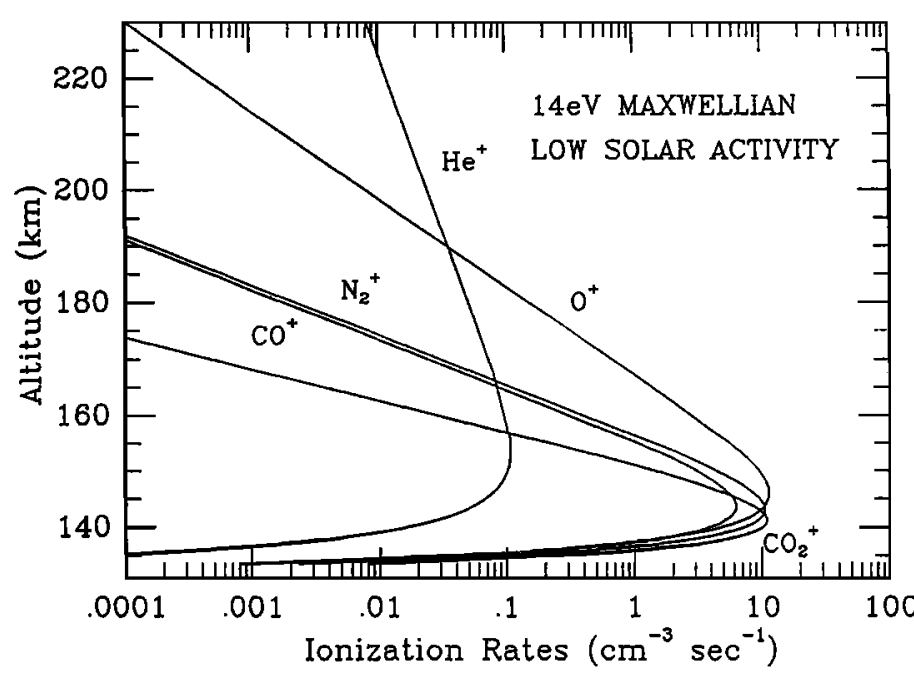

Fig. 2. Production rates of ions due to auroral precipitation for the same neutral model atmosphere as in Fig. 1. The spectrum of precipitating electrons was chosen to be that measured by Knudsen and Miller [1985], and the magnitude ( $51 \%$ of the downward traveling portion of the spectrum) was chosen to reproduce the measured $\mathrm{O}^{+}$maximum.

duces the observed value of $1.4 \times 10^{3} \mathrm{~cm}^{-3}$ near $155 \mathrm{~km}$. The computed ion density profiles for this model are shown in Figure 3. The maximum $\mathrm{O}_{2}^{+}$density is about $9.4 \times 10^{3} \mathrm{~cm}^{-3}$ near $144 \mathrm{~km}$, and, surprisingly, $O_{2}^{+}$is the major ion at all altitudes below $235 \mathrm{~km}$. An examination of the re-entry data suggests that that is the case for only about one-fourth of the orbits. The peak densities of the atomic ions $\mathrm{He}^{+}$, $\mathrm{C}^{+}$, and $\mathrm{N}^{+}$are all quite small, about 11,21 , and $19 \mathrm{~cm}^{-3}$, respectively. The ratios of $\mathrm{He}^{+} / \mathrm{O}^{+}, \mathrm{C}^{+} / \mathrm{O}^{+}$, and $\mathrm{N}^{+} / \mathrm{O}^{+}$ at $220 \mathrm{~km}$ are $0.007,0.011$, and 0.014 , respectively. These values are less than the averages obtained from the data by factors of 17 and 16 , for $\mathrm{C}^{+}$and $\mathrm{N}^{+}$, respectively, and by a fector of 65 for $\mathrm{He}^{+}$.

\section{Discussion and Concuusions}

Fow and Taylor [1990] suggested that, because $\mathrm{N}_{2}^{+}$and $\mathrm{CO}^{+}$are difficult to produce chemically, large values of mass-28 ion densities are evidence for significant electron precipitation. Kar et al. [1993] have examined the re-entry data, and presented evidence from the measured masa-28 ion densities that a significant amount of electron precipitation is occurring at low solar activity. The mass-28 ion densities in some of the re-entry orbits are quite large. The presence of precipitation would mean that the ion fluxes that we have assumed in our ion transport model are too large. Indeed, the $\mathrm{He}^{+}$peak density for the transport model is larger than the average measured value (about $90 \mathrm{~cm}^{-3}$ ) by about factor of 7 .

We have also found, however, that the auroral model, which was designed to reproduce the measured $\mathrm{O}^{+}$densities, does not fit the other atomic ions very well at all. The $\mathrm{He}^{+}$maximum is smaller than the measured values by a factor of about 8 . The transport model does fit the atomic ion densities at high altitudes, because it was designed to do so. In contrast, the auroral model could not be made to fit the data. Increasing the precipitating electron fluxes will increase the densities of all the atomic ions, but will not alter their ratios substantially. Moreover, the electron flux required here to reproduce the measured $\mathrm{O}^{+}$maximum

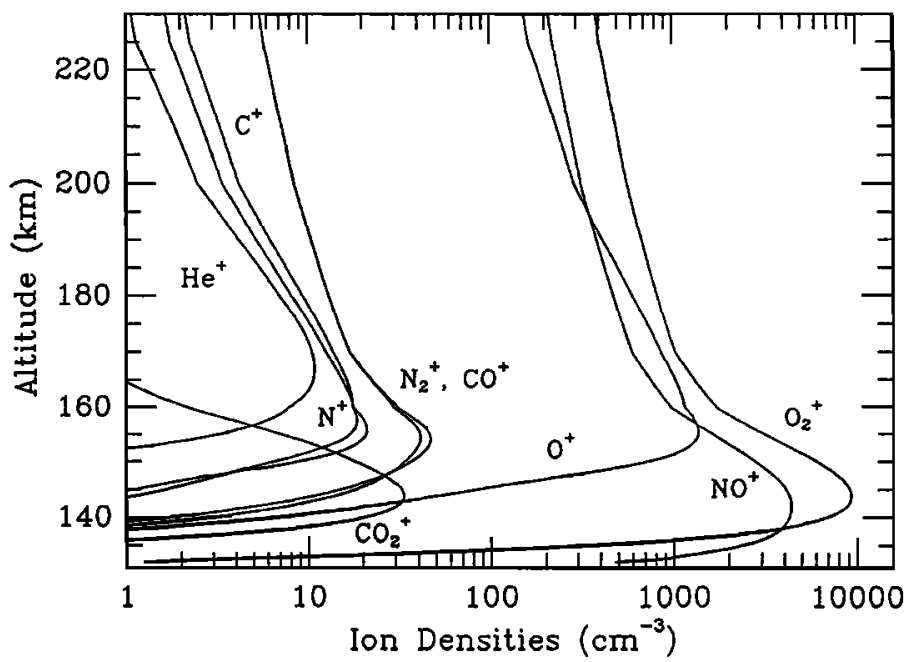

Fig. 3. Computed ion density profiles for the auroral model. The ion production rates for this model are shown in Fig. 2.

density is more than was found necessary to produce the atomic oxygen 1304 and 1356 A auroral emissions observed at high solar activity by the PV orbiter ultraviolet spectrometer [Fox and Stewart, 1991]. In addition, the aurora] intensities were observed to decrease markedly during solar minimum [A. I. F. Stewart, private communication].

The neutral model is a potentially significant source of uncertainty here. The $\mathbf{C}$ densities were computed within the model, and their is a siseable chance that the actual densities are substantially different from the computed ones. The $\mathrm{N}$ and He densities were taken from the VTS3 model of Hedin et al. [1983], which, while it is does predict densities for low solar activity, is based on high solar activity data. That model will probably be modified with the inclusion of the re-entry data. A glance at the re-entry data from the ONMS suggests that the He densities may be larger than predicted, but the difference should not be more than a factor of about two.

It has been suggested that the day-to-night transport of ions is cut off at low solar activity [Knudsen, 1988; Kliore et al., 1991]. Cravens et al. [1983] showed that the nightward flux depends on a large supply of ions on the dayside, which, at high solar activity, is evidenced by a high ionopause. It has been assumed that at low solar activity, the decreased solar flux would lead to dayside ion densities that are too low for efficient transport. Nonetheless, the observed $\mathrm{He}^{+}$ densities cannot be reproduced by the electron precipitation model. Therefore, we have come to the conclusion that, contrary to the prevailing wisdom, there are significant dayto-night fluxes of ions, at least in the pre-dawn bulge region, even at low solar activity.

Acknowledgements. This work has been supported in part by the National Aeronautics and Space Administration under grant NAGW-2958 from the Planetary Atmospheres Program and by a grant from the Venus Data Analysis Program.

\section{References}

Cravens, T. E., S. L. Crawford, A. F. Nagy and T. I. Gombosi, A two-dimensional model of the ionosphere of Venus, J. Geophys. Res., 88, 5595, 1983. 
Fox, J. L., The chemistry of metastable species in the Venugian ionosphere, Icarus $61,248,1982$. of the Venus thermosphere, Space Sci. Reviews, 55, 357, 1991.

Fox, J. L., The chemistry of the nightside ionosphere of Venus, Planet. Space Sci., 40, 1663, 1992.

Fox, J. L., and A. Dalgarno, Ionization, luminosity and heating of the upper atmosphere of Mars. J. geophys. Res., 84, 7315, 1979.

Fox, J. L. and A. I. F. Stewart, The Venus ultraviolet aurora: a soft electron source. J. Geophys. Res., 96, 9829, 1991.

Fox, J. L. and H. A. Taylor, Jr., A signature of electron precipitation in the nightside ionosphere of Venus, Geophys. Res. Lett., 17, 1625, 1990.

Fox, J. L., J. F. Brannon, A. I. F. Stewart, and H. S. Porter, Model Calculations of the nightside ionospheres of Venus and Mars, Bull. Amer. Astron. Soc., 84, 997, 1992.

Gringaus, K. I., M. I. Verigin, T. K. Breus and T. Gombosi, Electron currents measured in the optical shadow of Venus by the Venera-9 and Venera-10 satellites; the basic source of ionisation in the nightside ionosphere of Venus. Sov. Phys. Dokl., 28, 53, 1977.

Gringaus, K. I., M. I. Verigin, T. K. Breus, and T. Gombosi, The interaction of electrons in the optical umbra of Venus with the planetary atmosphere-The origin of the nighttime ionosphere. J. Geophys. Res., 84, 2123, 1979.

Hedin, A. E., H. B. Niemann, W. T. Kasprzak and A. Seiff, Global empirical model of the Venus thermosphere, $J$. Geophys. Res., 88, 73, 1983.

Kar, J., R. E. Hartle, J. M. Grebowsky, W. T. Kasprsak, T. M. Donahue, and P. A. Cloutier, Evidence of electron impact ionisation on the nightside of Venus from PVO/OIMS measurements near solar minimum, J. Geophys. Res., (in press), 1993.

Kliore, A. J., J. G. Luhmann, and M. H. G. Zhang, The effect of solar cycle on the maintenance of the nightside ionosphere of Venus, J. Geophys. Res., 96, 11,065, 1991.

Knudsen, W. C., Solar cycle changes in the morphology of the Venus ionosphere, J. Geophys. Res., 93, 8756, 1988.
Knudsen, W. C. and K. L. Miller, Pioneer Venus superthermal electron flux measurements in the Venus umbra, $J$. Geophys. Res., 90,2695, 1985.

Knudsen, W. C., K. Spenner, K. L. Miller and V. Novak, Transport of ionospheric $\mathrm{O}^{+}$ions across the Venus terminator and implications, J. Geophys. Res., 85, 7803, 1980. Miller, K. L., W. C., Knudsen, and K. Spenner, The dayside Venus ionosphere. I. Pioneer Venus retarding potential analyzer experimental observations, Icarus, 57, 386, 1984.

Niemann, H. B., W. T. Kasprzak, A. E. Hedin, D. M. Hunten and N. W. Spencer, Mass spectrometric measurements of the neutral gas composition of the thermosphere and exosphere of Venus, J. Geophys. Res., 85, 7817, 1980.

Porter, H. S., F. Varosi, and H. G. Mayr, Iterative solution of the multistream electron transport equation 1 . Comparison with laboratory beam injection experiments, $J$. Geophys. Res., 92, 5933, 1987.

Spenner, K., W. C. Knudsen, R. C. Whitten, P. F. Michelson, K. L. Miller and V. Novak, On the maintenance of the Venus nightside ionosphere: electron precipitation and plasma transport, J. Geophys. Res., 86, 9170, 1981.

Taylor, H. A., H. C. Brinton, S. J. Bauer, R. E. Hartle, P. A. Cloutier and R. E. Daniell, Global observations of the composition and dynamics of the ionosphere of Venus: implications for the solar wind interaction. J. Geophys. Res., 85, 7765, 1980.

J. F. Brannon and J. L. Fox, Marine Sciences Research Center, State University of New York at Stony Brook, Stony Brook, NY 11794.

H. S. Porter, Department of Computer Sciences, Furman University, Greenville, SC 29613.

(Received: July 6, 1993; accepted: August 13, 1993) 